\title{
Development Evaluation and Enlightenment on Renewable Energy Generation Dispatching Model
}

\author{
Junsong Qin ${ }^{1, a}$, Yashan Zhong ${ }^{1, b^{*}}$ and Dongxiao Niu ${ }^{1, c}$ \\ ${ }^{1}$ School of Economics and Management, North China Electric Power University, Beijing, China \\ ancepujun@163.com, bhongyashan132@163.com, niudx@126.com
}

Keywords: Renewable energy; Generation dispatching model; Grid; Development evaluation

\begin{abstract}
To ensure the security and stability operation and reliable power supply, it needs to take appropriate grid dispatching approaches to management, combining with the actual operation of the power grid parameters, such as voltage, current, frequency, load, considering the case of the production work. Generation dispatching model is important for the safety of grid security and stability. Scale renewable energy generation is an important way to promote green economic development and energy-saving emission reduction targets. However, wind power and photovoltaic power generation started late, and the technology is immature, scale renewable energy and power generation will have an impact on the traditional generation dispatching model. This paper classifies and compares the existing renewable energy generation dispatching model, and evaluates the renewable energy generation dispatching model of the UK and Northern Europe. In the base of Combining with China's implementation of energy-saving dispatching model, this paper got enlightenment in renewable energy generation dispatching model of China.
\end{abstract}

\section{Introduction}

To ensure the security and stability operation and reliable power supply, it needs to take appropriate grid dispatching approaches to management, combining with the actual operation of the power grid parameters, such as voltage, current, frequency, load, considering the case of the production work [1]. The grid dispatchers need to judge Grid security and economic operation status, and then command site operator or automatic control system to adjust the operation status.

Scale renewable energy generation is an important way to promote green economic development and energy-saving emission reduction targets [2,3]. Renewable energy includes hydropower, wind power, photovoltaic power generation and so on. In the renewable energy, wind power and photovoltaic power generation started late, and the technology is immature. Furthermore, the uncertainty of wind power has brought a lot of scheduling problems. Therefore, we need a renewable energy power generation scheduling model to ensure energy conservation and the safe operation of the power grid.

In the rest of this paper, we will classifies and compares the existing renewable energy generation dispatching model, and evaluates the renewable energy generation dispatching model of the UK and Northern Europe [4, 5]. In the base of Combining with China's implementation of energy-saving dispatching model, we will get enlightenment in renewable energy generation dispatching model of China.

\section{Britain Scheduling Mode Analyses}

Britain Electricity Market. The Britain is one of the nations who complete the electricity market reform firstly. It established a comprehensive system of electricity market in which generation, transmission, distribution, sale and scheduling are mutually independent. Moreover, it also established independent futures, spot trading market in order to avoid risks $[6,7]$.

The basic principle of the UK electricity market is to establish trading mechanism of generation and sale electricity market. It set up a wholesale market in generation side and a retail market in the 
sale of electric side. When the electricity delivers to users through transmission grid, power generation companies and retailers pay grid operators wheeling costs. UK Grid mainly regulates energy balance through market mechanisms. Only small part of it balanced through dispatching mechanism $[8,9]$.

British Dispatching Methods. As the British electricity market system has been relatively mature, scheduling is complete through the market. Therefore, it is still use market to ease after the access of renewable energy. Moreover, balancing member of control center will balance and dispatch in real-time [10].

After the access of renewable energy, there are two problems in generation dispatching. One is the forecasting of wind power, the other one is the scheduling backup costs.

The accuracy of wind power forecasting directly affects the power grid. However, the forecasting of wind speed, wind direction, barometric pressure and other meteorological factors are very complex. NGC hire a professional company to do some research for wind power forecasting. It has established an efficient forecasting system of wind power to ensure the operation of the electricity market and the real-time balance.

In the scheduling backup problem, market strategies have been taken to solve the problem of system congestion costs. Now the wind power policy of UK is "no wind curtailment", it means wind power has to transfer in full load. However, wind power is largely dependent on wind speed and other weather conditions, which causes large randomness wind power. Additionally the average load rate of wind power is not high. The series of reasons cause great challenge in active balance of the grid. A sudden increase of wind power output will lead to a increase in congesting costs of system. Usually the cost will be borne by grid. To address this problem, NGC still take market. With price guide, units declare increase or decrease load in the short-term standby market. Then dispatch center select unit with lowest price to adjust. After large-scale wind power grid, the backup capacity increased 7 to 8 time compared to before.

\section{Northern Europe Scheduling Mode Analysis}

Northern Europe Electricity Market. The Nordpool is the electricity-trading platform in Norway, Sweden, Finland, and Denmark, Covering more than 70 percent of the Nordic electricity trading. There are two spot market, day-ahead market and intraday market. Market participants were assigned to different tariff area. In all regions, the price is determined by buyers and sellers bid. It reflects supply and demand balance of electricity in Hourly intervals [11].

According to the length of time from the generation time, electricity market can be divided into three levels. The first level is day-ahead market. It is closed at 24 hours before power. In the market, buyers and sellers submit hourly quotations to the Power Exchange. Nordpool collects all quotations, and calculates the hourly marginal price based of supply and demand balance. The second level is intraday market, which closed at 1 hour before power. The third level is balance market, which balance the real time in the 30 minutes to 5 minutes before power. No matter which market, the buyers and seller has to production and use of electricity in the power supply time as soon as the trade build. Once one or both supply and demand of electricity contrary to the agreement, It will lead to unbalanced system. So the person who violates agreement is required to pay liquidated damages.

Northern Europe Dispatching Methods. The Nordic electricity market developed relatively well, electricity market dominated by the price plays a major role in supply and demand balance. About $95 \%$ to $97 \%$ of the power balance is achieved through the power market. Only about $5 \%$ to $3 \%$ of electricity achieves real-time balance through the grid scheduling mechanism. This feature determines that the grid dispatching is very limited in optimal allocation of resources, environmental protection and sustainable development. Related policy objectives achieve mainly by energy policy, environmental regulations, and the provisions of the market rules supplement the terms and license terms. 
Take Denmark as an example, Denmark is a country who has the highest proportion of wind power installed capacity around the world. Wind power installed capacity is $39.1 \%$ of the total in 2014 . Furthermore, the government plans to achieve $50 \%$ of the total generating capacity. Denmark set up a market mechanism which adapts the characteristics of the wind power. In the market, wind power is dispatched priority. What's more, there are some methods to make sure it, mainly in the following four areas.

Firstly, market mechanism that adapts the characteristics of the wind power must be set up. Wind power can fully participate in market competition in various stages of day-ahead market and intraday market. Because of the low margin cost, wind power can take the advantages and ensure priority scheduling. Secondly, accuracy of wind power forecasting must be improved. So it can provide technical support for wind power generation in the market and adjust plans. Wind power prediction is related to the safe and stable operation and the economic benefits of wind power companies. Thirdly, peaking capacity of system must be increased in order to provide protection for wind power priority scheduling. In the Danish electricity system, Danish power system, gas-fired units take a higher proportion, and the hydropower units take a higher proportion in Nordic power system. They are also available spare capacity to Denmark. The gas units and the hydropower units have a better performance in peaking, which can be a good adaptation of volatility and uncertainty of wind power. Finally, it is important to do the demand side management in order to assist wind power scheduling priority. in case of an emergency of operation system, demand-side management can ensure safe and stable operation of the system.

\section{Chinese Energy-efficient Scheduling Analysis and Enlightenment}

Chinese Energy-efficient Scheduling Analysis. In China, thermal power units take a large proportion. Under the background of environmental pollution, the government proposed an energy-efficient scheduling model to improve energy efficiency and reduce pollutant emissions. Under the premise of guaranteed power supply, energy-efficient scheduling model can priority scheduling renewable energy and efficiency thermal power units. So it can promote the energy efficiency of power industrial continuously, and ultimately achieve the purpose of energy saving.

There are many shortcomings in Chinese energy-efficient scheduling. Such as it lack of a clear approach to measure energy consumption and pollutant emissions of units. Energy-efficient scheduling is based on coal consumption and emission levels, but under normal circumstances, there are some differences between design coal consumption and actual coal consumption. With different conditions, coal consumption is not the same. It is difficult to measure unit coal consumption and a slight increase rate. So we need establish a clear approach to measure coal consumption and pollutant emissions of generators to ensure the smooth implementation of energy-saving scheduling.

In addition, there are some other issues. Firstly, some areas are more difficult to achieve energy scheduling. Secondly, the right of dispatching is chaos in some areas. Finally, there are some economy benefits problems and technical support issues should be solved.

Enlightenment of Renewable Energy Generation Dispatching Model. From the renewable energy dispatching model of countries above, we can get the following enlightenment.

(1) Carry out the policy that wind power transfer in full load. And establish a backup market to support services to ensure the safe operation of power.

(2) Wind power takes the advantages of low marginal cost to participate in market competition and ensure priority scheduling.

(3) Wind power takes part in market competition. It is need to establish a unified service provider for wind power prediction to provide wind power forecasting services. 


\section{Conclusion}

This paper classifies and compares the existing renewable energy generation dispatching model, and evaluates the renewable energy generation dispatching model of the UK and Northern Europe. These countries and areas have established power market and take the market as a means of dispatching.

There are many shortcomings in Chinese energy-efficient scheduling. Such as it lack of a clear approach to measure energy consumption and pollutant emissions of units, some areas are more difficult to achieve energy scheduling, some economy benefits problems and technical support and other issues.

In the base of Combining with China's implementation of energy-saving dispatching model, this paper got enlightenment in renewable energy generation dispatching model of China.

\section{References}

[1] M. Zeng, J.H. Duan, N. Li, the British experience in electrical and other bilateral Trade market model of reference, East China Electric Power, 2013, 41 (1): 1-4.

[2] A.Wen, W.F. Huang, Liu electricity trading balance mechanism in the UK electricity market, China Southern Power Grid Technology, 2014 (5): 1-5.

[3] Z.W Liu, Danish renewable energy priority scheduling practice analysis, technology economy market, 2014 (12): 92-92.

[4] Z.B Ma., British wind power development and dispatch an overview, Lau Yau Bor Power Science and Technology, 2011, 26 (1): 53-59.

[5] F. Rong, Y.M. Chu, L.Z. Yao, etc. Scheduling power saving review, Hydropower Engineering, 2011 (2): 178-181.

[6] B. Liu, T. Zhang, J.Y Zhou, Large-scale wind power generation plan of the development of the access method under study, Electrical applications, 2012 (24): 111-117.

[7] S. Lu, C.B. Li, J. Cao, etc. integrated coal consumption slightly increased rate of thermal power-based energy generation scheduling algorithm, Chinese CSEE, 2012, 32 (32): 1-7.

[8] J.C Shang. For a low-carbon economy power dispatching transaction Theory and Applications, Beijing, 2014.

[9] S.X. Wang , L.W. Ju , J.C Shang., etc. wind, hydro and pumped storage power station under a joint operation of energy-efficient scheduling environment optimization model and its application, Water Resources and Power, 2013 (4).

[10] J.Y. Gao, W. Wang based on energy-efficient scheduling method of coordination system of wind reservoir, Electronic production, 2013 (2).

[11] Information on http://www.nea.gov.cn/ 